\title{
Decision-making regarding withdrawal of life- sustaining treatment and the role of intensivists in the intensive care unit: a single-center study
}

\author{
Seo In Lee', Kyung Sook Hong ${ }^{2}$, Jin Park ${ }^{3}$, Young-Joo Lee ${ }^{4}$ \\ Departments of ${ }^{1} \mathrm{Critical}$ Care Medicine, ${ }^{2}$ Surgery and Critical Care Medicine, ${ }^{3}$ Neurology and Critical Care Medicine, and ${ }^{4}$ Anesthesiology and Critical Care \\ Medicine, Ewha Womans University College of Medicine, Seoul, Korea
}

Background: This study examined the experience of withholding or withdrawing life-sustaining treatment in patients hospitalized in the intensive care units (ICUs) of a tertiary care center. It also considers the role that intensivists play in the decision-making process regarding the withdrawal of life-sustaining treatment.

Methods: We retrospectively analyzed the medical records of 227 patients who decided to withhold or withdraw life-sustaining treatment while hospitalized at Ewha Womans University Medical Center Mokdong between April 9 and December 31, 2018.

Results: The 227 hospitalized patients included in the analysis withheld or withdrew from life-sustaining treatment. The department in which life-sustaining treatment was withheld or withdrawn most frequently was hemato-oncology (26.4\%). Among these patients, the most common diagnosis was gastrointestinal tract cancer (29.1\%). A majority of patients $(64.3 \%)$ chose not to receive any life-sustaining treatment. Of the 80 patients in the ICU, intensivists participated in the decision to withhold or withdraw life-sustaining treatment in 34 cases. There were higher proportions of treatment withdrawal and ICU-to-ward transfers among the cases in whom intensivists participated in decision making compared to those cases in whom intensivists did not participate ( $50.0 \%$ vs. $4.3 \%$ and $52.9 \%$ vs. $19.6 \%$, respectively).

Conclusions: Through their participation in end-of-life discussions, intensivists can help patients' families to make decisions about withholding or withdrawing life-sustaining treatment and possibly avoiding futile treatments for these patients.

Key Words: euthanasia; intensive care units; resuscitation orders; terminal care; withholding treatment

\section{INTRODUCTION}

End-of-life care and life-sustaining treatment withholding and withdrawal (LSTW) received little attention from intensive care unit (ICU) clinicians during the mid-20th century. During this time, ICU monitoring and critical care medicine was just beginning to develop, and most intensivists focused on extending patients' lives using advanced technology rather than comforting patients in their final days of life [1]. Despite intensivists' efforts to save lives, approximately 540,000 patients die in ICUs annually in the United States, accounting for $22.4 \%$ of all deaths in the country [2]. Ultimately, intensivists recognized that they are not only responsi-

\section{Original Article}

Received: March 20, 2020

Revised: May 29, 2020

Accepted: May 29, 2020

Corresponding author

Seo In Lee

Department of Critical Care

Medicine, Ewha Womans University

College of Medicine, 1071

Anyangcheon-ro, Yangcheon-gu,

Seoul 07985, Korea

Tel: +82-2-2650-5366

Fax: +82-507-992-8267

E-mail: becultured@naver.com

Copyright $(\odot 2020$ The Korean Society of Critical Care Medicine

This is an Open Access article distributed under the terms of Creative Attributions Non-Commercial License (https:/I creativecommons.org/li-censes/by-nc/4.0/) which permits unrestricted noncommercial use, distribution, and reproduction in any medium, provided the original work is properly cited. 
ble for saving lives, but also providing end-of-life care to terminally ill patients [3]. Furthermore, ICU resources are limited, and delivery of nonbeneficial treatment can undermine patient dignity. Therefore, there has been growing emphasis on the importance of research and education regarding advanced care planning, end-of-life care, and LSTW $[1,4]$.

In South Korea, two prominent cases prompted public discussion regarding the decision to forego life-sustaining treatments (LSTs). The first case is the "Boramae Hospital Case (1997)." In this case, a doctor at Boramae Hospital withdrew life-sustaining mechanical ventilation from a patient who had suffered from a brain hemorrhage with the consent of the patient's wife. In doing so, this physician was charged with aiding a murder. The second case is "Grandma Kim's case (2008)," in which the Supreme Court ordered LSTW of a 77-year-old grandmother, Kim Ok-kyung, at the request of her family because she was in a persistent vegetative state [5-7]. These two conflicting court rulings involving LSTW confused clinicians. After these cases, there was growing public support in South Korea for enactment of the decision to forego LSTs.

After much discussion and public consultation, a law concerning "Hospice, palliative care, and withdrawal of life-sustaining treatment" was enacted in February 2016. A demonstration of the project was provided by the Korean Ministry of Health and Welfare before the law was enforced nationally on February 4, $2018[5,6]$. Thus far, this law has only been enforced for two years in Korea. Regardless, physicians use it to address their difficulties in making decisions regarding LSTW, because there is little precedent or research in clinical settings to which they can refer. Intensivists, in particular, encounter these difficulties often because of their constant exposure to critically ill patients.

It is of utmost importance to determine when to withhold or withdraw LST in critically ill patients in the ICU, as some medical interventions in this setting may be futile or against the wishes of terminally ill patients. LST for terminally ill patients without expected recoveries also leads to considerable cost $[8,9]$. Intensivists must not only concentrate on treating patients admitted to the ICU, but also address the redistribution of ICU resources. In addition, unlike the prior emphasis on medical paternalism, the approach has recently shifted to shared and engaged decision making among physicians, patients, and their families. This is particularly true regarding terminally ill patients, for whom a patient's autonomy must be respected. Therefore, it is important for intensivists to provide patients and their families with clinical information to help them to decide on the extent of LST in patients at the end

\section{KEY MESSAGES}

- Despite the enactment of a law regarding withdrawal of life-sustaining treatment, attending doctors who are not intensivists are less likely to withdraw life support than are intensivists.

- In the group in which intensivists participated in the decision-making process, intensivists helped patients' families to reach decisions.

- After life-sustaining treatment withholding and withdrawal decision, patients were transferred to the general wards significantly more often than they were in the group in which intensivist did not participate.

of life [10].

The purpose of this retrospective study was to identify the current status of decisions regarding LSTW for patients hospitalized in ICUs by reviewing cases that involved this at Ewha Womans University Medical Center Mokdong (EUMC-Mokdong). We also considered the role of ICU intensivists in the decision-making process regarding LSTW through separate examination of cases in which they participated in this process.

\section{MATERIALS AND METHODS}

\section{Study Design and Population}

The target population was patients aged $\geq 20$ years who were hospitalized at EUMC-Mokdong, which is a tertiary medical institution with approximately 800 beds (including 54 ICU beds). To perform a retrospective analysis, we collected the medical records from 227 patients who had decided to withdraw LST between April 9 (when the LST consulting team was launched and decisions regarding LSTW began to be made) and December 31, 2018.

We collected data from 88 ICU patients who decided to withdraw LST. However, we only analyzed the baseline characteristics of 80 of these patients, because the hospitalization process was not complete for eight patients within the medical record collection period. In EUMC-Mokdong, dedicated ICU intensivists treat patients hospitalized in every department through consultation with other departments by applying an open ICU model. In cases in which the attending physician did not choose to consult with intensivists, the physician independently decided whether to continue or discontinue LST without the intensivists' intervention. These patients were included in the control group.

Conversely, if the ICU was involved in cases in which the 
patient was receiving end-of-life care or who was terminally ill (and not responding to aggressive treatment), the intensivist consulted with the attending physician about withholding or withdrawing LST. If the physician judged that the patients would not survive despite aggressive treatment, the intensivists in charge communicated with patients' families to decide whether to withhold or withdraw LST, and to determine the extent of the treatment to be provided. These cases were included in the intensivist group.

If intensivists judged a patient to be nearing the end of their life with no chance of survival, they completed the "Judgment Sheet on Patients in the End-of-Life Process," along with the attending physicians in the relevant department, to decide whether to withdraw or withhold LST. This process also allowed the physicians to determine the extent of LST that would be provided based on interviews with the patient's family. If the patient's family so desired, the patient was transferred to a general ward, and the LSTW process was implemented. This process might involve extubation or the removal of a mechanical ventilator, and pain control.

We assigned the ICU patients into two groups depending on whether or not intensivists participated in the decisionmaking process to withdraw LST. We analyzed the differences between the two groups by comparing whether the decision was made to withdraw or withhold LST, the duration of ICU hospitalization, and the patients' progress.

\section{Data Collection}

We collected and analyzed basic clinical data and information related to decisions regarding LSTW for patients hospitalized in EUMC-Mokdong who made such decisions and met the selection criteria. With regard to the basic clinical data, we recorded each patient's age, sex, medical department, diagnosis, hospitalization ward, and Acute Physiology and Chronic Health Evaluation (APACHE) II score at the time of ICU hospitalization. We recorded the following information with regard to the decision to withdraw LST: the date on which the decision was made; the type of judgment; whether an intensivist participated in writing the patient's end-of-life judgment sheet and completing the form for the decision to withdraw LST; LSTW interventions; and whether the decision to withdraw or withhold LST was implemented.

The clinical data were collected using Excel data and electronic medical records based on the forms for the decision to withdraw or withhold LST. These forms were as follows: confirmation of the patient's intention to withhold or withdraw LST (advance directives or statements from patients' families), confirmation of the patient's family members' intention regarding the LSTW decision, implementation of the decision to withhold or withdraw LST, application to access medical records, judgment sheet for patients in the end-of-life process, terminal patient's management record card, and application for advance directives. The withdrawal or withholding of LST was performed by dedicated LSTW nurses in the hospital. Based on these data, we analyzed the characteristics of the patients who decided to withhold or withdraw LST. We also collected a list of ICU patients, and divided them into the two groups as described above. Between these two groups, we analyzed differences in the results regarding LSTW, such as: patients' progress, length of stay in ICU, days before death after the decision was made to withdraw LST, and implementation of the decision to withhold or withdraw LST. This study was approved by the Institutional Review Board at EUMC-Mokdong (IRB No. 2019-02-034). Informed consent was waived.

\section{Statistical Analysis}

IBM SPSS ver. 25.0 (IBM Corp., Armonk, NY, USA) was used for the data analysis. With regard to the patients' basic clinical data, continuous variables (such as age and APACHE II scores) were expressed numerically as means \pm standard deviations. In cases in which the variables were not distributed normally, the variables are expressed as medians (interquartile ranges). Other nominal variables are expressed as numbers and percentages. We used a chi-square test and Fisher's exact test to compare nominal variables that represented the basic clinical data and differences between the two groups. An independent t-test was performed to compare the mean values. A MannWhitney U-test was used when the dependent variables were not normally distributed. The significance level was set at $\mathrm{P}<$ 0.05 .

\section{RESULTS}

\section{Baseline Characteristics of the Participants}

The general characteristics of the 227 patients who met the selection criteria during the study period are shown in Table 1. The department that decided to withhold or withdraw LST most frequently was the Department of Hemato-oncology $(\mathrm{n}=60,26.4 \%)$. Within this department, the most common diagnosis was cancer, and more specifically, gastrointestinal tract cancer $(n=66,29.1 \%)$. Regarding the chosen LSTW interventions, the proportion of patients who decided not to receive any LST was the largest (64.3\%). The remaining patients chose individual LST interventions (Table 2). Of these, the pa- 
Table 1. General characteristics of patients who made decisions regarding LST during admission (admission patients) and during ICU admission (ICU patients)

\begin{tabular}{|c|c|c|}
\hline Variable & $\begin{array}{l}\text { Admission patient } \\
\quad(n=227)\end{array}$ & $\begin{array}{l}\text { ICU patient } \\
(n=80)\end{array}$ \\
\hline Age (yr) & $71.88 \pm 13.59$ & $72.5 \pm 14.42$ \\
\hline \multicolumn{3}{|l|}{ Sex } \\
\hline Male & $92(40.5)$ & $50(62.5)$ \\
\hline Female & $135(59.5)$ & $30(37.5)$ \\
\hline \multicolumn{3}{|l|}{ Ward/ICU } \\
\hline Ward & 139 (61.2) & - \\
\hline Intensive care unit & 88 (38.8) & - \\
\hline \multicolumn{3}{|l|}{ Admission department } \\
\hline Hemato-oncology & $60(26.4)$ & $6(7.5)$ \\
\hline Pulmonology & 29 (12.8) & $11(13.8)$ \\
\hline Neurosurgery & $29(12.8)$ & $23(28.7)$ \\
\hline Neurology & $24(10.6)$ & $10(12.5)$ \\
\hline General surgery & $22(9.7)$ & $8(10.0)$ \\
\hline Gastrointestinal medicine & $21(9.3)$ & $4(5.0)$ \\
\hline Cardiology & $10(4.4)$ & $7(8.8)$ \\
\hline Nephrology & 8 (3.5) & $4(5.0)$ \\
\hline Urology & $8(3.5)$ & $1(1.3)$ \\
\hline Obstetrics \& gynecology & $6(2.6)$ & $1(1.3)$ \\
\hline Emergency medicine & $3(1.3)$ & $2(2.5)$ \\
\hline Infectious medicine & $3(1.3)$ & $1(1.3)$ \\
\hline Orthopedic surgery & $2(0.9)$ & $2(2.5)$ \\
\hline Allergy medicine & $1(0.4)$ & 0 \\
\hline Family medicine & $1(0.4)$ & 0 \\
\hline \multicolumn{3}{|l|}{ Admission diagnosis } \\
\hline Gl tract cancer & $66(29.1)$ & 7 (8.8) \\
\hline Cerebral hemorrhage & $23(10.1)$ & $23(28.7)$ \\
\hline Urologic cancer & $19(8.4)$ & $4(5.0)$ \\
\hline Lung cancer & $17(7.5)$ & $1(1.3)$ \\
\hline Cerebral infarction & $15(6.6)$ & $4(5.0)$ \\
\hline Pneumonia & $13(5.7)$ & $8(10.0)$ \\
\hline Hematologic cancer & 8 (3.5) & $3(3.8)$ \\
\hline Gynecologic cancer & $6(2.6)$ & $1(1.3)$ \\
\hline Breast cancer & $6(2.6)$ & $0(0.0)$ \\
\hline Hypoxic brain injury & $6(2.6)$ & $4(5.0)$ \\
\hline Septic shock & $5(2.2)$ & $4(5.0)$ \\
\hline Brain tumor & $5(2.2)$ & $0(0.0)$ \\
\hline Status epilepticus & $4(1.8)$ & $3(3.8)$ \\
\hline Gl hemorrhage & $3(1.3)$ & $1(1.3)$ \\
\hline Chronic pulmonary failure & $3(1.3)$ & $3(3.8)$ \\
\hline Renal failure & $3(1.3)$ & 0 \\
\hline Liver failure & $3(1.3)$ & $2(2.5)$ \\
\hline Myocardial infarction & $2(0.9)$ & $1(1.3)$ \\
\hline Heart failure & $2(0.9)$ & $2(2.5)$ \\
\hline Melanoma & $2(0.9)$ & 0 \\
\hline Central nerve system infection & $2(0.9)$ & $1(1.3)$ \\
\hline Cholangitis/cholecystitis & $2(0.9)$ & $1(1.3)$ \\
\hline Other $^{\mathrm{a}}$ & $12(5.3)$ & $7(8.8)$ \\
\hline
\end{tabular}

Values are presented as mean \pm standard deviations or number (\%). Data might be duplicated.

LST: life-sustaining treatment; ICU: intensive care unit; GI: gastrointestinal.

aOther diagnoses: acute respiratory distress syndrome, delirium, drowsiness, internal carotid artery stenosis, intestinal obstruction, myelopathy, Parkinson disease, pulmonary thromboembolism, Takayasu arteritis, trauma.
Table 2. Chosen interventions for withdrawing or withholding LST by group

\begin{tabular}{lcc}
\hline Variable & $\begin{array}{c}\text { Admission } \\
\text { patient } \\
(\mathrm{n}=227)\end{array}$ & $\begin{array}{c}\text { ICU patient } \\
(\mathrm{n}=80)\end{array}$ \\
\hline Intervention for withholding and withdrawing LST & \\
All & $146(64.3)$ & $32(40.0)$ \\
Cardiopulmonary resuscitation & $73(32.2)$ & $48(60.0)$ \\
Ventilator & $49(21.6)$ & $28(35.0)$ \\
Hemodialysis & $56(24.7)$ & $34(42.5)$ \\
Chemotherapy & $11(4.8)$ & $8(10.0)$ \\
Form for LSTW decisions & & \\
Agreement of all family members & $118(52.0)$ & $52(65.0)$ \\
Statement from the patient's family & $63(27.7)$ & $23(28.7)$ \\
Advance directives & $46(20.3)$ & $5(6.3)$ \\
\hline
\end{tabular}

Values are presented as number (\%). Data might be duplicated. LST: life-sustaining treatment; ICU: intensive care unit; LSTW: life-sustaining treatment withholding or withdrawal.

tients who chose not to receive cardiopulmonary resuscitation accounted for the largest proportion (32.2\%; multiple responses). Regarding the forms for LSTW decisions, "Confirmation of the patient's family members' intention regarding the LSTW decision (agreement of all family members of unconscious patients)" accounted for the largest proportion of patients (52\%), followed by “Confirmation of the patient's intention to withhold or withdraw LST (statement from the patient's family; 27.7\%)." The number of cases in which advance directives for LST were prepared accounted for the lowest proportion of patients $(20.3 \%)$ (Table 2).

\section{Clinical Characteristics of ICU Patients}

In total, 80 ICU patients decided to withhold or withdraw LST. The department that made LSTW in the ICU decisions most frequently was the Department of Neurosurgery (23 patients, $28.7 \%$ ). The most common diagnosis in this department was cerebral hemorrhage (Table 1).

Of the ICU patients who decided to withhold or withdraw LST, 32 (40.0\%) decided to withhold or withdraw all LST, while the remaining 48 decided to decline cardiopulmonary resuscitation (Table 2). In addition, 34 (42.5\%) and 28 (35.0\%) patients declined dialysis and mechanical ventilation, respectively (multiple responses). The number of cases in which LST was withheld was higher than those in whom LST was withdrawn ( $76.3 \%$ vs. $23.8 \%)$. In the ICU, most patients died ( $\mathrm{n}=70$, 87.5\%) after the LSTW decision was made. The median number of days from ICU admission to LSTW decision was 8.0 
Table 3. Clinical statuses and progress of ICU patients who decided to withhold or withdraw LST in EUMC-Mokdong Hospital

\begin{tabular}{|c|c|}
\hline Variable & Value \\
\hline \multicolumn{2}{|l|}{ Type of ICU } \\
\hline Cardiac & $3(3.8)$ \\
\hline Emergency & $16(20.0)$ \\
\hline Medical & $27(33.8)$ \\
\hline Neurological & $21(26.3)$ \\
\hline Surgical & $13(16.3)$ \\
\hline APACHE II score & $28.7 \pm 7.80$ \\
\hline ICU LOS after LSTW decision (day) & $2.5(2.0-5.0)$ \\
\hline Day to death after LSTW decision & $3.0(2.0-5.0)$ \\
\hline Day to LSTW decision after ICU admission & $8.0(3.3-17.8)$ \\
\hline \multicolumn{2}{|l|}{ Comorbidity } \\
\hline HTN & $40(50.0)$ \\
\hline Cancer & 27 (33.8) \\
\hline DM & $23(28.8)$ \\
\hline Stroke & $19(23.8)$ \\
\hline Heart disease & $17(21.3)$ \\
\hline CKD & $9(11.3)$ \\
\hline LC & $8(10.0)$ \\
\hline Lung disease & $8(10.0)$ \\
\hline Other $^{\mathrm{a}}$ & $4(5.0)$ \\
\hline \multicolumn{2}{|l|}{ Major cause of ICU admission } \\
\hline Neurological disorder & $31(38.8)$ \\
\hline Respiratory failure & $23(28.8)$ \\
\hline Sepsis or septic shock & $10(12.5)$ \\
\hline Cardiac arrest & $6(7.5)$ \\
\hline Hypovolemic shock & $5(6.3)$ \\
\hline Heart failure & $3(3.8)$ \\
\hline Liver failure & $2(2.5)$ \\
\hline \multicolumn{2}{|l|}{ LST before LSTW decision } \\
\hline $\mathrm{CPR}$ & $11(13.8)$ \\
\hline Ventilator & $62(77.5)$ \\
\hline Vasopressor or inotropic drugs & $61(76.3)$ \\
\hline Transfusion & $49(61.3)$ \\
\hline Hemodialysis & $13(16.3)$ \\
\hline \multicolumn{2}{|l|}{ Withholding or withdrawing LST } \\
\hline Withholding & $61(76.3)$ \\
\hline Withdrawing & $19(23.8)$ \\
\hline \multicolumn{2}{|l|}{ Progress after LSTW decision } \\
\hline Expired & 70 (87.5) \\
\hline Transferred to another hospital & $6(7.5)$ \\
\hline Discharged & $4(5.0)$ \\
\hline
\end{tabular}

Values are presented as or number $(\%)$, mean \pm standard deviation, or median (interquartile range). Data might be duplicated.

ICU: intensive care unit; LST: life-sustaining treatment; EUMC-Mokdong: Ewha Womans University Medical Center Mokdong; APACHE: Acute Physiology and Chronic Health Evaluation; LOS: length of stay; LSTW: life-sustaining treatment withholding or withdrawal; HTN: hypertension; DM: diabetes mellitus; CKD: chronic kidney disease; LC: liver cirrhosis; CPR: cardiopulmonary resuscitation.

${ }^{a}$ Other comorbidities: epilepsy, Parkinson disease, Takayasu arteritis.
(3.3-17.8). The average number of days between the decision and death was 3.0 (2.0-5.0) (Table 3).

\section{Comparing the Intensivists and Control Groups}

Of the 80 ICU patients who decided to withhold or withdraw LST, the number of patients for whom intensivists participated in the LSTW decisions was 34 (Table 4). The patients' age, disease severity (identified via the APACHE II scores), and comorbidities, did not differ significantly between patients for whom intensivists did and did not participate in the LSTW decisions (age, $\mathrm{P}=0.950$; APACHE II, $\mathrm{P}=0.814$ ).

The most common admission department in the intensivists group was neurosurgery (64.7\%) and in the control group, pulmonology $(23.9 \%, \mathrm{P}<0.001)$. The most prevalent comorbidity was hypertension (HTN) in both groups. Neurological disorders were the major cause of ICU admission in the intensivists group, while respiratory failure was the most prevalent cause of ICU admission in the control group ( $\mathrm{P}=0.002)$. In the intensivist group, the most common LST before the LSTW decision was mechanical ventilation ( $94.1 \%$ vs. $65.2 \%, \mathrm{P}=0.002)$. In the control group, the administration of vasoactive drugs was the most common LST ( $80.4 \%$ vs. $70.6 \%, \mathrm{P}=0.306)$.

Among the cases in which intensivists participated in the decision, the proportion of cases involving LST withdrawal was higher than that involving LST withholding $(50.0 \%$ vs. $4.3 \%$, respectively, $\mathrm{P}<0.001)$. In addition, the proportion of patients who moved to the general ward from the ICU following the LSTW decision was significantly higher in the group in whom intensivists participated in the LSTW decision than it was when intensivists did not participate (52.9\% vs. $19.6 \%$, $\mathrm{P}=0.002$ ). The median duration of ICU hospitalization after the LSTW decision was shorter (2 days) when intensivists participated in the decision than it was when they did not (3 days), although this difference was not significant. The progress made by the patients in these two groups did not differ significantly.

\section{Comparison between Withdrawn Group and Withheld Group}

In order to identify the variables affecting the LST withholding or withdrawing, we divided the participants into a "withdrawn" group and a "withheld" group. There were 19 patients withdrawn from LST and 61 patients in whom LST was withheld (Table 5). There were no significant differences in age, APACHE II score, comorbidities, or days to LSTW decision between the two groups.

Neurosurgery was the most common department to withdraw LST (78.9\%), while the most common department for 
Table 4. Differences in characteristics between patients for whom intensivists did (intensivists group) and did not (control group) participate in LSTW decisions

\begin{tabular}{|c|c|c|c|}
\hline Variable & Intensivists group $(n=34)$ & Control group $(n=46)$ & P-value \\
\hline Age (yr) & $72.62 \pm 13.35$ & $72.41 \pm 15.31$ & 0.950 \\
\hline APACHE II score (point) & $28.94 \pm 7.95$ & $28.52 \pm 7.78$ & 0.814 \\
\hline ICU LOS after LSTW decision & $2.0(1.0-4.25)$ & $3.0(2.0-5.0)$ & 0.203 \\
\hline Day to death after LSTW decision & $3.0(2.0-5.0)$ & $3.0(1.0-4.5)$ & 0.212 \\
\hline Day to LSTW decision after ICU admission & $8.5(4.0-23.0)$ & $8.0(2.0-14.0)$ & 0.168 \\
\hline Admission department & & & $<0.001$ \\
\hline Neurosurgery & $22(64.7)$ & $1(2.2)$ & \\
\hline General surgery & $8(23.5)$ & 0 & \\
\hline Pulmonology & 0 & $11(23.9)$ & \\
\hline Neurology & $1(2.9)$ & $9(19.6)$ & \\
\hline Cardiology & 0 & $7(15.2)$ & \\
\hline Hemato-oncology & 0 & $6(13.0)$ & \\
\hline Gastrointestinal medicine & 0 & $4(8.7)$ & \\
\hline Nephrology & 0 & $4(8.7)$ & \\
\hline Orthopedic surgery & $2(5.9)$ & 0 & \\
\hline Emergency medicine & 0 & $2(4.3)$ & \\
\hline Infectious medicine & 0 & $1(2.2)$ & \\
\hline Urology & $1(2.9)$ & 0 & \\
\hline Obstetrics \& Gynecology & 0 & $1(2.2)$ & \\
\hline \multicolumn{4}{|l|}{ Comorbidity } \\
\hline HTN & $17(50.0)$ & $23(50.0)$ & 1.000 \\
\hline Cancer & $12(35.3)$ & $15(32.6)$ & 0.816 \\
\hline $\mathrm{DM}$ & $12(35.3)$ & $11(23.9)$ & 0.266 \\
\hline Stroke & $5(14.7)$ & $14(30.4)$ & 0.119 \\
\hline Heart disease & $10(29.4)$ & $7(15.2)$ & 0.125 \\
\hline CKD & $5(14.7)$ & $4(8.7)$ & 0.484 \\
\hline LC & $6(17.6)$ & $2(4.3)$ & 0.066 \\
\hline Lung disease & $1(2.9)$ & $7(15.2)$ & 0.129 \\
\hline Other ${ }^{\mathrm{a}}$ & $2(5.9)$ & $2(4.3)$ & 1.000 \\
\hline Major cause of ICU admission & & & 0.002 \\
\hline Neurological disorder & $22(64.7)$ & 9 (19.6) & \\
\hline Respiratory failure & $5(14.7)$ & $18(39.1)$ & \\
\hline Sepsis or septic shock & $3(8.8)$ & 7 (15.2) & \\
\hline Cardiac arrest & $1(2.9)$ & $5(10.9)$ & \\
\hline Hypovolemic shock & $2(5.9)$ & $3(6.5)$ & \\
\hline Heart failure & 0 & $3(6.5)$ & \\
\hline Liver failure & $1(2.9)$ & $1(2.2)$ & \\
\hline \multicolumn{4}{|l|}{ LST before LSTW decision } \\
\hline CPR & $2(5.9)$ & 9 (19.6) & 0.016 \\
\hline Ventilator & $32(94.1)$ & $30(65.2)$ & 0.002 \\
\hline Vasopressor or inotropic drugs & $24(70.6)$ & $37(80.4)$ & 0.306 \\
\hline Transfusion & $20(58.8)$ & $29(63.0)$ & 1.000 \\
\hline Hemodialysis & $5(14.7)$ & $8(17.4)$ & 0.702 \\
\hline Withholding or withdrawing LST & & & $<0.001$ \\
\hline Withholding & $17(50.0)$ & $44(95.7)$ & \\
\hline Withdrawing & $17(50.0)$ & $2(4.3)$ & \\
\hline ICU-to-ward transfers after LSTW decision & & & 0.002 \\
\hline Ward transfer & $18(52.9)$ & 9 (19.6) & \\
\hline Not transferred & $16(47.1)$ & $37(80.4)$ & \\
\hline Progress after LSTW decision & & & 0.877 \\
\hline Expired & $29(85.3)$ & $41(89.1)$ & \\
\hline Transferred to another hospital & $3(8.8)$ & $3(6.5)$ & \\
\hline Discharged & $2(5.9)$ & $2(4.3)$ & \\
\hline
\end{tabular}

Values are presented as mean \pm standard deviation, median (interquartile range), or number (\%). Data might be duplicated.

LSTW: life-sustaining treatment withholding or withdrawal; APACHE: Acute Physiology and Chronic Health Evaluation; ICU: intensive care unit; LOS: length of stay; HTN: hypertension; DM: diabetes mellitus; CKD: chronic kidney disease; LC: liver cirrhosis; LST: life-sustaining treatment; CPR: cardiopulmonary resuscitation.

${ }^{2}$ Other comorbidities: epilepsy, Parkinson's disease, Takayasu's arteritis. 
Table 5. Differences in characteristics between patients who had LST withdrawn (withdrawn group) and withheld (withheld group)

\begin{tabular}{|c|c|c|c|}
\hline Variable & Withdrawn group $(n=19)$ & Withheld group $(n=61)$ & P-value \\
\hline Age (yr) & $67.84 \pm 16.48$ & $73.95 \pm 13.54$ & 0.169 \\
\hline APACHE II score (point) & $31.21 \pm 7.32$ & $27.92 \pm 7.85$ & 0.109 \\
\hline ICU LOS after LSTW decision & $2.0(1.0-3.0)$ & $3.0(2.0-5.0)$ & 0.040 \\
\hline Day to death after LSTW decision & $2.0(1.0-3.0)$ & $4.0(2.0-5.0)$ & 0.058 \\
\hline Day to LSTW decision after ICU admission & $8.0(6.0-14.0)$ & $8.0(2.5-19.5)$ & 0.431 \\
\hline Admission department & & & $<0.001$ \\
\hline Neurosurgery & $15(78.9)$ & $8(13.1)$ & \\
\hline General surgery & 0 & $8(13.1)$ & \\
\hline Pulmonology & 0 & $11(18.0)$ & \\
\hline Neurology & $1(5.3)$ & $9(14.8)$ & \\
\hline Cardiology & 0 & $7(11.5)$ & \\
\hline Hemato-oncology & 0 & $6(9.8)$ & \\
\hline Gastrointestinal medicine & 0 & $4(6.6)$ & \\
\hline Nephrology & 0 & $4(6.6)$ & \\
\hline Orthopedic surgery & $1(5.3)$ & $1(1.6)$ & \\
\hline Emergency medicine & $1(5.3)$ & $1(1.6)$ & \\
\hline Infectious medicine & 0 & $1(1.6)$ & \\
\hline Urology & 0 & $1(1.6)$ & \\
\hline Obstetrics \& gynecology & $1(5.3)$ & 0 & \\
\hline \multicolumn{4}{|l|}{ Comorbidity } \\
\hline HTN & $7(36.8)$ & $33(54.1)$ & 0.189 \\
\hline Cancer & $5(26.3)$ & $22(36.1)$ & 0.433 \\
\hline DM & $6(31.6)$ & $17(27.9)$ & 0.755 \\
\hline Stroke & $2(10.5)$ & $17(27.9)$ & 0.121 \\
\hline Heart disease & $7(36.8)$ & $10(16.4)$ & 0.104 \\
\hline CKD & $3(15.8)$ & $6(9.8)$ & 0.473 \\
\hline LC & $4(21.1)$ & $4(6.6)$ & 0.086 \\
\hline Lung disease & $1(5.3)$ & $7(11.5)$ & 0.431 \\
\hline Other ${ }^{\mathrm{a}}$ & $1(5.3)$ & $3(4.9)$ & 0.952 \\
\hline Major cause of ICU admission & & & $<0.001$ \\
\hline Neurological disorder & $15(78.9)$ & $16(26.2)$ & \\
\hline Respiratory failure & 0 & $23(37.7)$ & \\
\hline Sepsis or septic shock & 0 & $10(16.4)$ & \\
\hline Cardiac arrest & $2(10.5)$ & $4(6.6)$ & \\
\hline Hypovolemic shock & $2(10.5)$ & $3(4.9)$ & \\
\hline Heart failure & 0 & $3(4.9)$ & \\
\hline Liver failure & 0 & $2(3.3)$ & \\
\hline \multicolumn{4}{|l|}{ LST before LSTW decision } \\
\hline $\mathrm{CPR}$ & $3(15.8)$ & $8(13.1)$ & 0.768 \\
\hline Ventilator & $19(100.0)$ & $43(70.5)$ & 0.005 \\
\hline Vasopressor or inotropic drugs & 14 (73.7) & $47(77.0)$ & 0.764 \\
\hline Transfusion & $11(57.9)$ & $38(62.3)$ & 0.731 \\
\hline Hemodialysis & $2(10.5)$ & $11(18.0)$ & 0.723 \\
\hline
\end{tabular}

Values are presented as mean \pm standard deviation, median (interquartile range), or number (\%). Data might be duplicated.

LST: life-sustaining treatment; APACHE: Acute Physiology and Chronic Health Evaluation; ICU: intensive care unit; LOS: length of stay; LSTW: life-sustaining treatment withholding or withdrawal; HTN: hypertension; DM: diabetes mellitus; CKD: chronic kidney disease; LC: liver cirrhosis; CPR: cardiopulmonary resuscitation.

a0ther comorbidities: epilepsy, Parkinson disease, Takayasu arteritis. 
deciding to withhold LST was pulmonology (18.0\%, $\mathrm{P}<0.001)$. The most frequent cause for ICU admission in the withdrawn group was neurological disorder $(78.9 \%)$, while respiratory failure accounted for the largest number of ICU admissions in the withheld group $(37.7 \%, \mathrm{P}<0.001)$. Considering the type of LST, mechanical ventilation was significantly more frequently administered in the withdrawn group than it was in the withheld group ( $100.0 \%$ vs. $70.5 \%, \mathrm{P}=0.005)$.

\section{DISCUSSION}

This retrospective, single-institution study examined how LSTW has been conducted clinically since the law concerning "Hospice, palliative care, and withdrawal of life-sustaining treatment" was implemented in Korea. We analyzed differences between cases in which ICU intensivists did and did not participate in LSTW decisions.

There were no statistically significant differences in age, APACHE II score, comorbidities, or days from ICU admission to LSTW decision among the study participants. There were, however, significant differences between the two groups with regard to the medical department, main cause of ICU admission, and use of mechanical ventilation. Specifically, the most common department in the withheld group was neurosurgery, and the most prevalent cause of ICU admission was neurological disease. These findings are similar to the results of a previous study showing that neurological diagnosis is associated with withholding or withdrawing LST in ICU patients [11].

When comparing the intensivists group to the control group, we found significant differences in the medical department and the main cause of ICU admission. Neurological disorders were the most common cause of ICU admission in the intensivist group. This finding may be related to the fact that neurosurgery is the department in which intensivists are most frequently consulted. In addition, there was a significant difference between the two groups with regard to the medical department, which may have been influenced by the adoption of an open ICU model in the hospital where the study was performed. Intensivists in this hospital do not manage all patients admitted to the ICU. Instead, they participate in the care of patients for whom they are consulted by the attending physicians. Therefore, there appears to be a difference in the departments that frequently refer to intensivists and those that do not do so frequently depending on the tendency of each physician. Although there were differences between the two groups with regard to the medical departments, reason for ICU admission, and type of LST performed, we found that the intensivists group tended to withdraw LST rather than withhold LST compared to the control group.

In Asia, there is a weaker tendency toward LSTW for terminal ICU patients relative to that observed in the United States and Europe [12-14]. Moreover, Korea shows a stronger tendency toward active LST relative to that of other Asian countries for the same type of terminal patients (i.e., hypoxic-ischemic encephalopathy resulting from septic shock). In addition, Korea showed a tendency to withhold, but not withdraw, LST, even for patients who have "no chance of recovery to a meaningful life" [12]. This tendency may be attributable to many factors, such as religion, social culture, and the absence of a legal system $[12,14,15]$.

However, our results demonstrated that attending doctors who were not ICU intensivists considered LST withdrawal more negatively than they did LST withholding. This tendency exists despite the fact that the legal system in Korea allows LSTW. There is a widely held opinion that there is no ethical difference between LST withdrawal and withholding $[3,16,17]$. Despite this, medical professionals' unconditional insistence on only withholding LST (rather than withdrawing it) may not only prolong patients' suffering, but also increase the cost of medical care resulting from prolonged LST. These choices may also lead to long-term economic burden to patients' families and society in general $[17,18]$.

Our results showed that the proportion of patients who decided to withdraw LST and the number of cases in whom patients were transferred to general wards from the ICU were higher when intensivists were involved in the LSTW decisions than they were when they were not. Although this difference was not statistically significant, the average duration of ICU hospitalization for patients in whom intensivists participated in the LSTW decisions was shorter than that observed for patients in whom intensivists did not participate. This finding may be due to the fact that, in the group in which intensivists participated in the LSTW decisions, both the attending physicians and intensivists extensively communicated with the patients' families and helped them to make informed decisions. In this way, appropriate communication between medical staff and patients' families can improve family members' understanding of LST and help them to decide whether to withhold or withdraw treatment. This communication also allows patients to pass away in the presence of their family members in a private ward if this is requested by their families. Previous research has shown that high-quality communication between medical staff and families reduces the duration of ICU hospitalization $[19,20]$. In addition, other studies have found that 
sufficient communication can reduce the mental burden experienced by patients' families and increase their satisfaction [21-23]. In addition, intensivists could not only reduce the length of time for which terminally ill patients receiving nonbeneficial treatment suffer by reducing the duration of ICU hospitalization, but also redistribute limited ICU resources appropriately [24].

This study has several limitations. It was a retrospective, single-institution study. Because of our hospital's policy, there were significant differences between the intensivist group and control group with regard to the medical department and main reason for ICU admission. The study therefore may have been subject to selection bias because of differences between the two groups. In addition, because this study was focused on a small number of cases, we were unable to perform multivariate analysis between the intensivist and control groups. Given the study design, we are unable to identify causal relationships between the reported outcomes and the presence of intensivists' participation. In addition, this study did not evaluate family members' satisfaction with the LSTW decisions according to group. A well-designed, large-scale study is needed to examine these issues in the future.

The burden of ICU treatment is increasing worldwide [25], and the role of intensivists in end-of-life care will expand gradually. In the future, intensivists will need to triage the use of ICU resources and face increasing difficulties in determining when to move terminally ill patients from intensive treatment to palliative care. The results of this study suggest that intensivists can reduce patients' suffering and the cost of medical treatment by communicating with patients' families and ultimately reducing the duration of ICU hospitalization.

In the ICU, intensivists are not only responsible for saving the lives of critically ill patients, but also of addressing these patients' quality of life. Therefore, intensivists must fully understand the ethical issues and legal systems that are related to LSTW decisions. In addition, intensivists must recognize the importance of appropriate communication with the families of terminally ill patients.

\section{CONFLICT OF INTEREST}

No potential conflicts of interest relevant to this article were reported.

\section{ACKNOWLEDGMENTS}

We thank the dedicated LSTW nurses in Ewha Womans Uni- versity Medical Center Mokdong for their help in data collection.

\section{ORCID}

Seo In Lee

https://orcid.org/0000-0001-7036-6233

Kyung Sook Hong https://orcid.org/0000-0002-8022-5693

Jin Park

https://orcid.org/0000-0002-4597-6344

Young-Joo Lee

https://orcid.org/0000-0002-6512-3891

\section{AUTHOR CONTRIBUTIONS}

Conceptualization: SIL, JP, YJL. Data curation: SIL. Formal analysis: SIL, KSH. Methodology: SIL, JP, KSH. Project administration: SIL, YJL. Visualization: SIL, KSH. Writing-original draft: SIL, JP. Writing-review \& editing: all authors.

\section{REFERENCES}

1. Luce JM. End-of-life decision making in the intensive care unit. Am J Respir Crit Care Med 2010;182:6-11.

2. Angus DC, Barnato AE, Linde-Zwirble WT, Weissfeld LA, Watson RS, Rickert T, et al. Use of intensive care at the end of life in the United States: an epidemiologic study. Crit Care Med 2004;32:638-43.

3. Curtis JR, Vincent JL. Ethics and end-of-life care for adults in the intensive care unit. Lancet 2010;376:1347-53.

4. Azoulay E, Metnitz B, Sprung CL, Timsit JF, Lemaire F, Bauer $\mathrm{P}$, et al. End-of-life practices in 282 intensive care units: data from the SAPS 3 database. Intensive Care Med 2009;35:62330.

5. Park SY. Decisions on life-sustaining treatment at the end of life. Korean J Med 2018;93:75-9.

6. Lee YS. Euthanasia: a misunderstood term. J Korean Med Assoc 2012;55:1163-70.

7. Choi K. Legal and ethical issues regarding end-of-life care in Korea. Dev Soc 2016;45:151-64.

8. Baek MS, Koh Y, Hong SB, Lim CM, Huh JW. Effect of timing of do-not-resuscitate orders on the clinical outcome of critically ill patients. Korean J Crit Care Med 2016;31:229-35.

9. Park JH, Koh SO, Cho JS, Na S. Evaluation of informed consent for withholding and withdrawal of life support in Korean intensive care units. Korean J Crit Care Med 2015;30:73-81

10. Shin K, Mok JH, Lee SH, Kim EJ, Seok NR, Ryu SS, et al. The current status of medical decision-making for dying patients in a medical intensive care unit: a single-center study. Korean J Crit Care Med 2014;29:160-5. 
11. Kranidiotis G, Gerovasili V, Tasoulis A, Tripodaki E, Vasileiadis I, Magira E, et al. End-of-life decisions in Greek intensive care units: a multicenter cohort study. Crit Care 2010;14:R228.

12. Phua J, Joynt GM, Nishimura M, Deng Y, Myatra SN, Chan YH, et al. Withholding and withdrawal of life-sustaining treatments in intensive care units in Asia. JAMA Intern Med 2015;175:36371.

13. Vincent JL. Forgoing life support in western European intensive care units: the results of an ethical questionnaire. Crit Care Med 1999;27:1626-33.

14. Yaguchi A, Truog RD, Curtis JR, Luce JM, Levy MM, Mélot C, et al. International differences in end-of-life attitudes in the intensive care unit: results of a survey. Arch Intern Med 2005; 165:1970-5.

15. Kwon I, Koh Y, Yun YH, Heo DS, Seo SY, Kim H, et al. A study of the attitudes of patients, family members, and physicians toward the withdrawal of medical treatment for terminal patients in Korea. Korean J Med Ethics 2010;13:1-16.

16. Sprung CL, Cohen SL, Sjokvist P, Baras M, Bulow HH, Hovilehto S, et al. End-of-life practices in European intensive care units: the Ethicus Study. JAMA 2003;290:790-7.

17. Carlet J, Thijs LG, Antonelli M, Cassell J, Cox P, Hill N, et al. Challenges in end-of-life care in the ICU. Statement of the 5th International Consensus Conference in Critical Care: Brussels, Belgium, April 2003. Intensive Care Med 2004;30:770-84.

18. Khandelwal N, Engelberg RA, Benkeser DC, Coe NB, Curtis JR. End-of-life expenditure in the ICU and perceived quality of dying. Chest 2014;146:1594-603.

19. Gruenberg DA, Shelton W, Rose SL, Rutter AE, Socaris S, McGee G. Factors influencing length of stay in the intensive care unit. Am J Crit Care 2006;15:502-9.

20. Ahrens T, Yancey V, Kollef M. Improving family communications at the end of life: implications for length of stay in the intensive care unit and resource use. Am J Crit Care 2003;12: 317-23.

21. Truog RD, Campbell ML, Curtis JR, Haas CE, Luce JM, Rubenfeld GD, et al. Recommendations for end-of-life care in the intensive care unit: a consensus statement by the American College [corrected] of Critical Care Medicine. Crit Care Med 2008;36:953-63.

22. Lautrette A, Darmon M, Megarbane B, Joly LM, Chevret S, Adrie C, et al. A communication strategy and brochure for relatives of patients dying in the ICU. N Engl J Med 2007;356: 469-78.

23. McDonagh JR, Elliott TB, Engelberg RA, Treece PD, Shannon SE, Rubenfeld GD, et al. Family satisfaction with family conferences about end-of-life care in the intensive care unit: increased proportion of family speech is associated with increased satisfaction. Crit Care Med 2004;32:1484-8.

24. Siegel MD. End-of-life decision making in the ICU. Clin Chest Med 2009;30:181-94.

25. Adhikari NK, Fowler RA, Bhagwanjee S, Rubenfeld GD. Critical care and the global burden of critical illness in adults. Lancet 2010;376:1339-46. 